\title{
Optimalisasi Formula Default Pada Amibroker Untuk Analisis Teknikal Pada Pasar Saham
}

\author{
Ridho Hisbi Sulaiman, I Made Agus Dwi Suarjaya, Anak Agung Ketut Agung Cahyawan \\ Wiranatha \\ Jurusan Teknologi Informasi, Fakultas Teknik, Universitas Udayana \\ Bukit Jimbaran, Bali, Indonesia, telp. (0361) 701806 \\ e-mail: ridhohisbi@gmail.com, agussuariaya@it.unud.ac.id, agung.cahyawan@unud.ac.id
}

\begin{abstract}
Abstrak
Penelitian ini bertujuan mengoptimalisasi sebuah formula default pada Amibroker menggunakan Bahasa AFL dengan beberapa algoritma yang dirancang agar para trader di pasar saham dapat melakukan analisis teknikal dan mengetahui langkah apa yang dapat diambil selanjutnya pada pasar saham. Formula default yang sudah dioptimalisasi memberikan informasi berupa tampilan chart. Para pengguna formula default yang sudah dioptimalisasi dapat mengetahui tindakan selanjutnya yang dapat diperoleh diambil dengan melihat sinyal buy atau sell yang tampil pada chart. Hasil dari penelitian nantinya diharapkan formula default yang dioptimalisasi dapat menjalankan fungsi-fungsi sebagaimana mestinya. Kesimpulan yang dapat ditarik dari penelitian ini adalah hingga saat ini formula default pada Amibroker yang sudah dioptimalisasi sebelumnya telah dapat menampilkan chart yang dapat memberikan analisis teknikal bagi pengguna berupa kondisi buy atau sell yang ditandai dengan sinyal berupa panah, menampilkan area resistance dan area support untuk membatasi keuntungan dan kerugian yang dapat diperoleh dari saham yang dimiliki.
\end{abstract}

Kata kunci: Saham, Amibroker, AFL, Analisis Teknikal

\begin{abstract}
This study aims to optimize a default formula in Amibroker using the AFL language with several algorithms designed so that traders in the stock market can carry out technical analysis and know what steps will be taken next on the stock market. The optimized default formula provides information in the form of a chart view. On the chart of the optimized default formula, users can find out the next action to be taken by looking at the buy or sell signals that appear on the chart. The results of this research are expected to optimize the default formula that can run functions as they should. A conclusion that can be drawn from this research is that up to now the default formula on the previously optimized Amibroker has been able to display charts that can provide technical analysis for users in the form of buy or sell conditions marked by signals in the form of arrows, displaying resistance and support areas for limit the profits and losses to be gained from shares owned.
\end{abstract}

Keywords: Stock, Amibroker, AFL, Technical Analysis

\section{Pendahuluan}

Dunia pasar saham bisa dikatakan sudah bukan hal asing ditelinga masyarakat di Indonesia. Investasi jangka panjang dan membuka bisnis dengan modal sedikit menjadi alasan bagi sebagian besar trader (orang yang berkecimpung di dunia saham) pemula untuk terjun ke dunia saham. Kurangnya pengetahuan dan petunjuk dalam pengambilan keputusan di dunia saham membuat para trader pemula di Indonesia sebagian besar kurang mendapatkan profit (keuntungan), putus asa dan pergi meninggalkan pasar saham, dan beranggapan bahwa bisnis di dunia saham sama halnya dengan judi (karena susah untuk diprediksi). Stigma-stigma seperti itu yang membuat orang-orang baru yang ingin terjun ke dunia saham sampai berpikir dua kali untuk melakukan keputusannya.

Amibroker merupakan perangkat lunak yang berguna untuk analisis teknikal canggih agar para pengguna mengetahui langkah selanjutnya yang diambil pada pasar saham [1]. 
Amibroker disematkan dengan bermacam-macam indikator dengan berbagai variasi yang dapat diadaptasi sesuai dengan kebutuhan pengguna, sehingga pengguna memiliki analisis yang lebih matang dalam menentukan keuntungan maupun kerugian [1]. Jika hanya memiliki AmiBroker saja kurang cukup bagi trader pemula karena dapat membingungkan trader dalam membaca grafik-grafik yang ditampilkan tanpa adanya instruksi dan probabilitas untuk trader mendapatkan profit yang masih kurang jelas. Amibroker memiliki bahasa pemrograman AFL (Amibroker Formula Language) yang digunakan oleh pengguna dalam membuat indikator dan algoritma sistem trading sesuai dengan pengguna tersebut inginkan [1]. Formula default pada Amibroker perlu dioptimalisasi dengan indikator-indikator tertentu agar memudahkan para trader pemula khususnya di Indonesia dalam membuat suatu keputusan di pasar saham Indonesia dan meningkatkan probabilitas mendapatkan profit untuk para trader yang menggunakan formula tersebut.

Mengetahui keadaan dunia pasar saham dan amibroker, didapatkan tujuan dari penulisan ini, antara lain untuk mengetahui alur data dan gambaran umum antara Amibroker, Sekuritas, dan Pengguna, untuk mengetahui indikator dan fungsi yang digunakan dalam perancangan formula AFL, dan mengetahui hasil backtest dan uji coba secara manual menggunakan formula yang sudah dioptimalisasi pada amibroker untuk menentukan probabilitas menang dari trader. Batasan masalah dari optimalisasi yang dimaksud dalam penelitian yaitu optimalisasi yang dilakukan hanya sebatas menambahkan 3 buah fungsi, parameter dan algoritma yang ditampilkan berupa indikator.

Penelitian terkait yang memprakarsai penelitian ini dirancang dan dibuat sebagaimana mestinya [2][3][4][5] yang dimana meskipun konteks yang diteliti berbeda dari penelitian ini, penelitian terkait memiliki tujuan utama yang sama dengan penelitian ini, yaitu melakukan optimalisasi suatu sistem dengan menggunakan metode/algoritma yang sudah dirancang agar kinerja maupun alur dari sistem tersebut lebih efisien dari sebelumnya.

\section{Metodologi Penelitian}

Gambaran umum dibentuk memiliki tujuan untuk mengetahui apa saja yang terjadi pada sistem, seperti masukan, proses, hingga keluaran yang dihasilkan berdasarkan data yang telah diolah. Gambaran umum dari penelitian "Optimalisasi Formula Default pada Amibroker untuk Analisis Teknikal pada Pasar Saham" dapat dilihat pada Gambar 1.

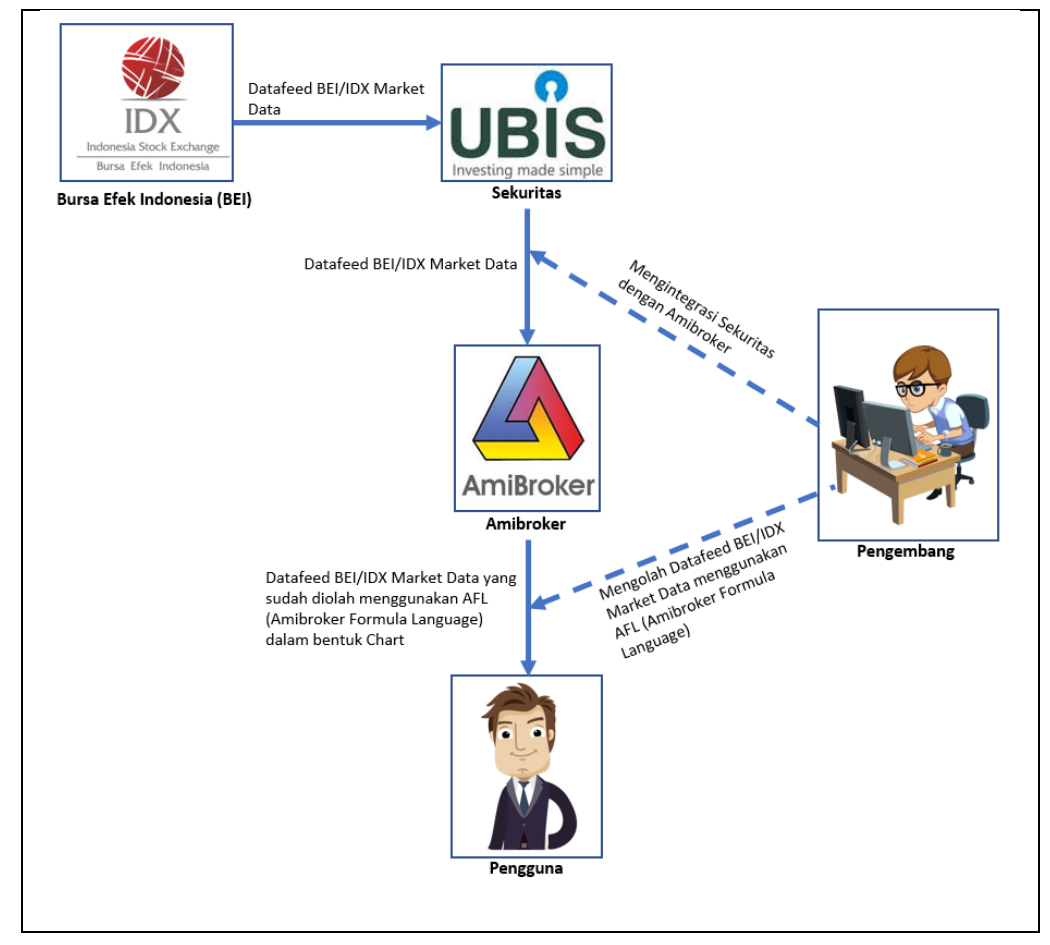

Gambar 1. Gambaran umum 
Gambar 1 merupakan Gambaran Umum sistem Amibroker. Gambaran umum dimulai dari PT.bursa efek Indonesia mengirimkan datafeed BEI/IDX Market data yang berisi data mengenai saham-saham yang tergabung dalam bursa efek Indonesia ke sekuritas, lalu sekuritas mengirimkan datafeed BEI/IDX Market data dari PT.bursa efek Indonesia ke Amibroker dengan bantuan developer, selanjutnya pengembang mengolah datafeed BEI/IDX Market data yang masuk ke Amibroker menggunakan AFL (Amibroker Formula Language) berdasarkan algoritma-algoritma yang ditentukan. Hasil dari datafeed BEI/IDX Market data yang sudah diolah oleh pengembang menggunakan AFL berdasarkan algoritma-algoritma yang ditentukan ditampilkan dalam bentuk grafik kepada pengguna yang ingin melakukan analisis teknikal dari suatu saham.

\subsection{Alur Data}

Alur data adalah aliran data dari sebuah proses atau sistem. Alur data dibentuk memiliki tujuan untuk mengetahui bagaimana alur data yang terjadi antara Sekuritas dengan Amibroker. Alur data dari penelitian "Optimalisasi Formula Default pada Amibroker untuk Analisis Teknikal pada Pasar Saham" dapat dilihat pada Gambar 2.

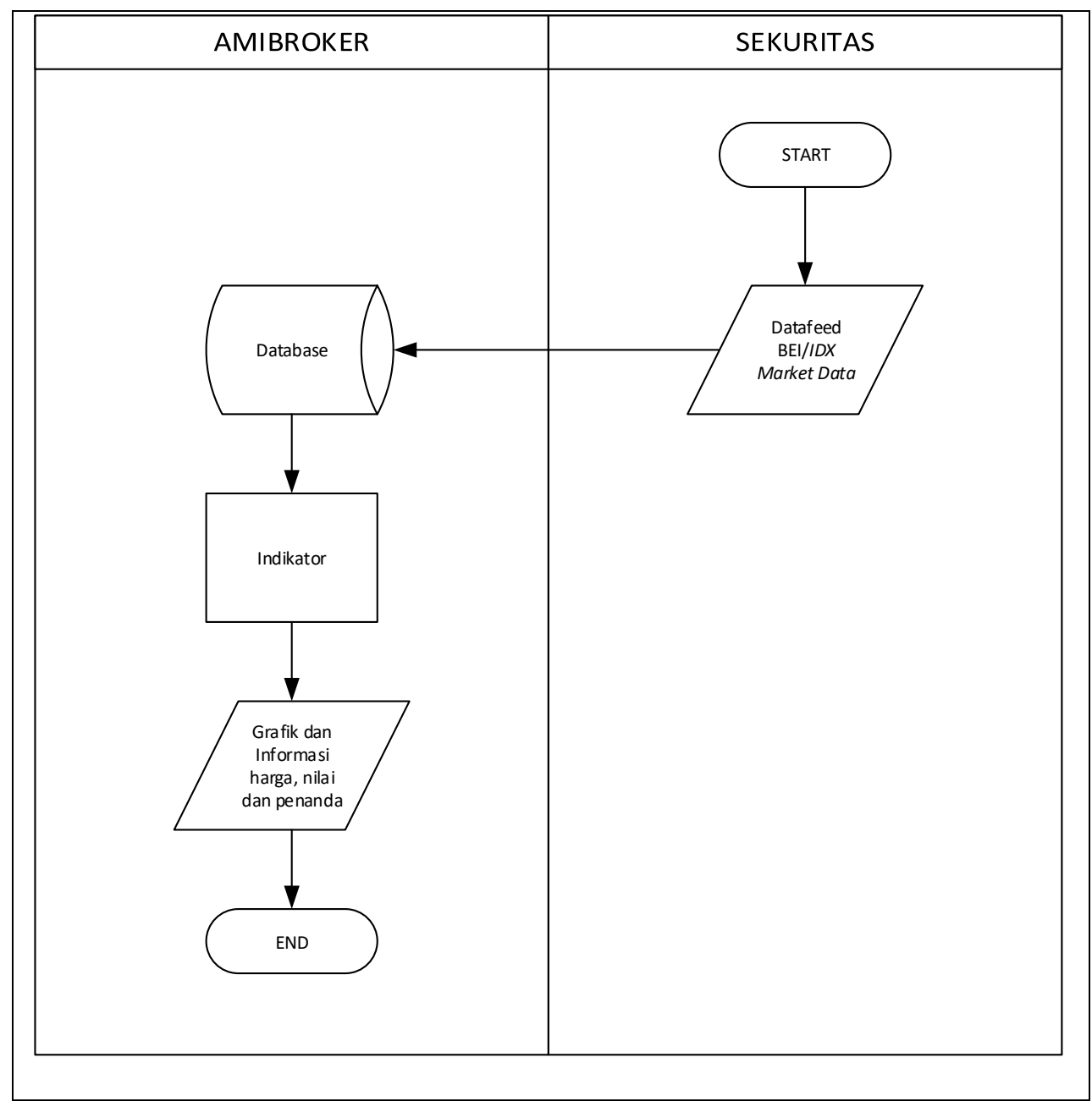

Gambar 2. Alur data

Gambar 2 merupakan Gambaran Umum dari sistem Amibroker yang dimulai dari proses import data berupa datafeed dari sekuritas ke database Amibroker untuk disimpan. Data yang sudah disimpan sebelumnya pada database diolah menggunakan indikator dalam bentuk formula yang sudah dirancang sebelumnya menggunakan metode-metode yang berlaku. Indikator yang sudah dikustom sebelumnya akan dibungkus ke dalam formula yang berformat .afl karena menggunakan Bahasa pemrograman Amibroker Formula Language. 
Proses pengolahan data telah selesai, data tersebut berubah menjadi informasi berupa grafik, harga, nilai, dan penanda yang sudah ditentukan sebelumnya pada formula agar trader dapat mengetahui langkah selanjutnya yang akan diambil pada bursa saham, khususnya pada perusahaan saham yang dipilih oleh trader.

\section{$2.2 \quad$ Pseudocode}

Mengoptimalisasi formula default pada Amibroker yang dilakukan terdapat beberapa algoritma-algoritma yang tergabung dalam bentuk formula yang dibuat untuk menentukan kondisi dari indikator-indikator yang digunakan pada formula dalam pembentukan sistem analisis teknikal. Algoritma-algoritma pada formula diekstrak menjadi pseudocode agar memudahkan pembaca dalam mengerti algoritma-algoritma yang sudah dirancang sebelumnya pada formula. Pseudocode dari algoritma-algoritma yang tergabung dalam formula default yang sesudah maupun sebelum dioptimalkan pada Amibroker dapat dijelaskan pada pembahasan selanjutnya.

\subsection{Formula Default pada Amibroker}

Formula default pada Amibroker merupakan formula yang sudah tertanam pada Amibroker yang ditampilkan saat pengguna baru membuka Amibroker untuk yang pertama kalinya. Formula tersebut disisipkan beberapa algoritma-algoritma yang sudah dirancang sebelumnya oleh pengembang agar lebih optimal dalam urusan membaca keadaan suatu saham. Pseudocode dari algoritma formula default pada Amibroker dapat dilihat pada Kode Program 1.

Mengatur pilihan chart (mode default, chart menampilkan tanggal);

Algoritma membuat candlestick \{

Deklarasi:

$\mathrm{C}=$ harga close:

Deskripsi:

Menampilkan plot grafik(berdasarkan C, memberikan nama fungsi "Close", dengan parameter warna default dan memberikan nama fungsi "Color", dengan style candlestick, dengan nilai minimun dan maximun dari plot yaitu 0 , dengan Xshift 0 , dengan posisi Z-axis yaitu 1, dan dengan nilai lebar yaitu 1 pixel);

\section{Kode Program 1. Pseudocode formula Default}

Algoritma dari formula default pada Amibroker hanya menggunakan harga close dari saham yang ditentukan sebagai variabel dalam pembentukan grafik. Grafik yang ditampilkan berdasarkan algoritma formula default pada Amibroker berbentuk candlestick, yang dimana candlestick merupakan grafik yang biasa digunakan dalam menganalisa keadaan suatu saham. Algoritma dari formula default pada Amibroker hanya menampilkan sebatas pergerakan harga saham yang ditentukan berdasarkan variabel close.

\subsection{Kondisi Buy atau Sell}

Dirancangnya algoritma dalam menentukan kondisi buy atau sell dengan tujuan agar pengguna yang menggunakan chart dari amibroker dengan formula yang sudah dioptimalisasi sebelumnya dapat memiliki opsi pada pasar saham terkait langkah selanjutnya yang dapat diambil. Pseudocode dari algoritma dalam menentukan kondisi buy atau sell dapat dilihat pada Kode Program 2.

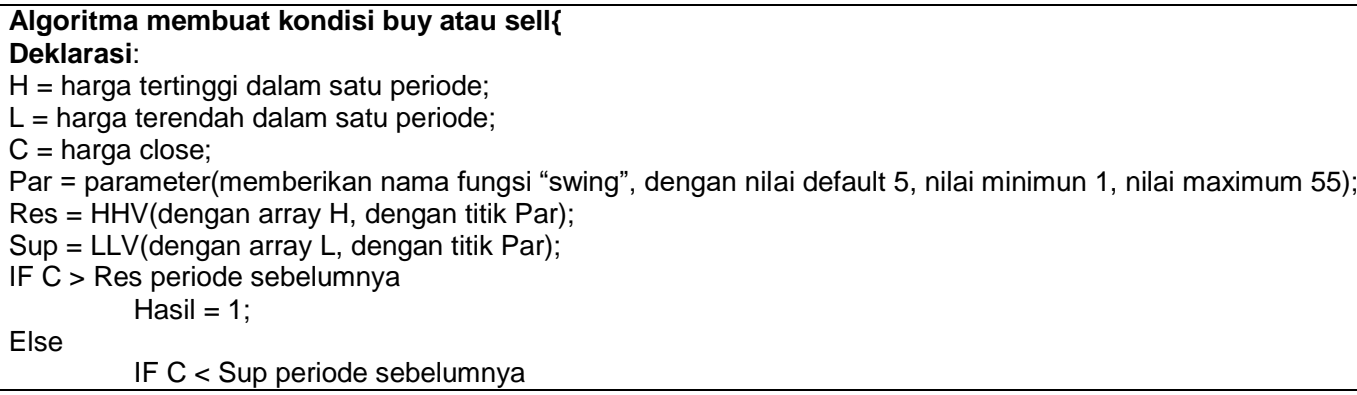




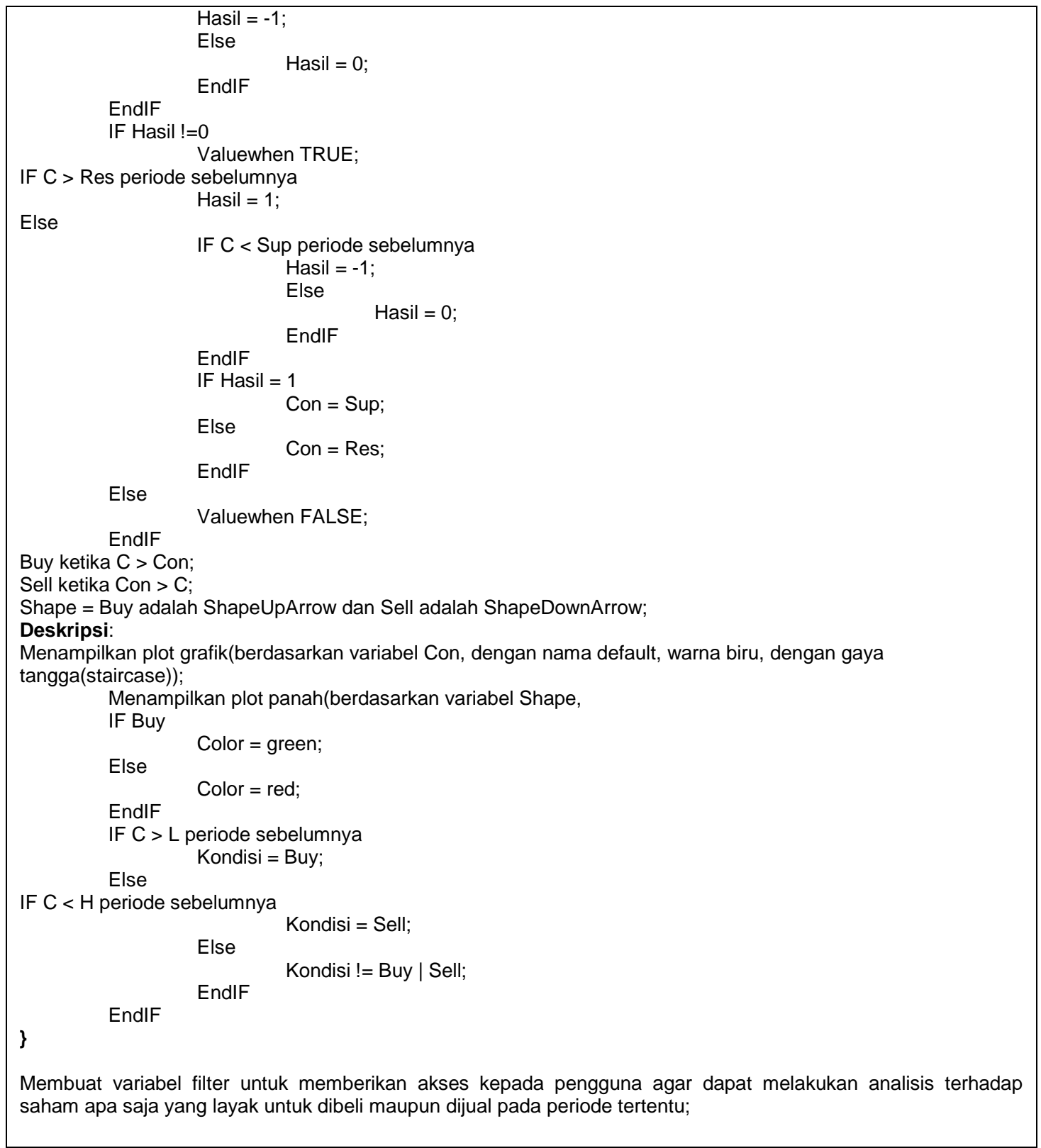

\section{Kode Program 2. Pseudocode kondisi Buy atau Sell}

Pseudocode dari algoritma dalam menentukan kondisi buy atau sell, dipergunakan data high, low, dan close pada harga suatu saham yang dipilih sebelumnya agar algoritma dalam menentukan kondisi buy atau sell dapat berjalan dan menentukan kondisi yang tepat. Output yang dihasilkan dari algoritma dalam menentukan kondisi buy atau sell berupa panah hijau sebagai penanda sinyal buy bagi pengguna dan panah merah sebagai penanda sinyal sell. Tidak ada panah sama sekali pada suatu periode yang ditentukan, artinya pada saat itu pengguna disarankan untuk tidak melakukan aksi apapun (tidak buy maupun sell).

\subsection{Kondisi Area Support dan Area Resistance}

Dirancangnya algoritma dalam menentukan kondisi area support dan area resistance dengan tujuan agar pengguna yang menggunakan chart dari amibroker dengan formula yang sudah dioptimalisasi sebelumnya dapat mengetahui batasan-batasan kerugian (area support) dan keuntungan (area resistance) yang bisa dicapai apabila pengguna tersebut melakukan aksi buy per periode pada saat itu juga. Area support dan area resistance memiliki beberapa level agar pengguna dapat memiliki beberapa pertimbangan dalam menentukan batasan keuntungan 
dan kerugian. Pseudocode dari algoritma dalam menentukan kondisi trend dapat dilihat pada Kode Program 3.

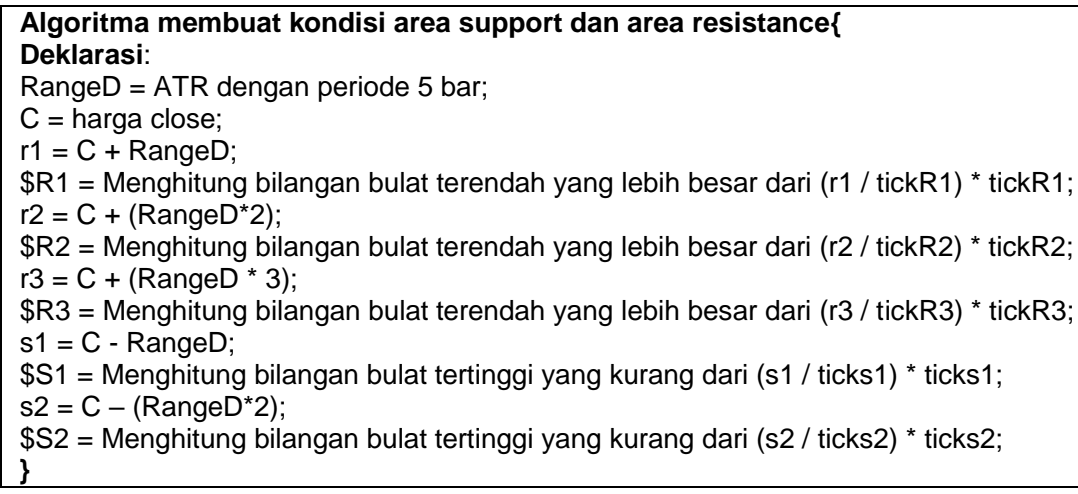

\section{Kode Program 3. Pseudocode kondisi Trend}

Pseudocode dari algoritma dalam menentukan kondisi trend, dipergunakannya data close dan ATR (average true range) pada harga suatu saham yang dipilih sebelumnya agar algoritma dalam menentukan kondisi trend dapat berjalan dan menentukan kondisi yang tepat. Output yang dihasilkan dari algoritma dalam menentukan kondisi trend berupa tulisan yang menunjukan area support maupun area resistance dengan beberapa level/tahapan yang berbeda. Semakin tinggi dari level area, maka semakin luas batasan harga support/resistance yang ditampilkan.

\subsection{Membuat Darvas Box}

Darvas Box merupakan indikator yang hanya menggambar garis di atas harga high dan low, dan kemudian menyesuaikan harga tersebut sebagai bentuk harga high dan harga low baru pada suatu saham [2]. Dirancangnya algoritma dalam membuat Darvas Box dengan tujuan agar pengguna yang menggunakan chart dari amibroker dengan formula yang sudah dioptimalisasi sebelumnya dapat memperkirakan pergerakan harga per periode yang ditentukan dengan mengandalkan Darvas Box sebagai patokan yang tergabung dalam chart. Pseudocode dari algoritma dalam menentukan membuat Darvas Box dapat dilihat pada Kode Program 4.

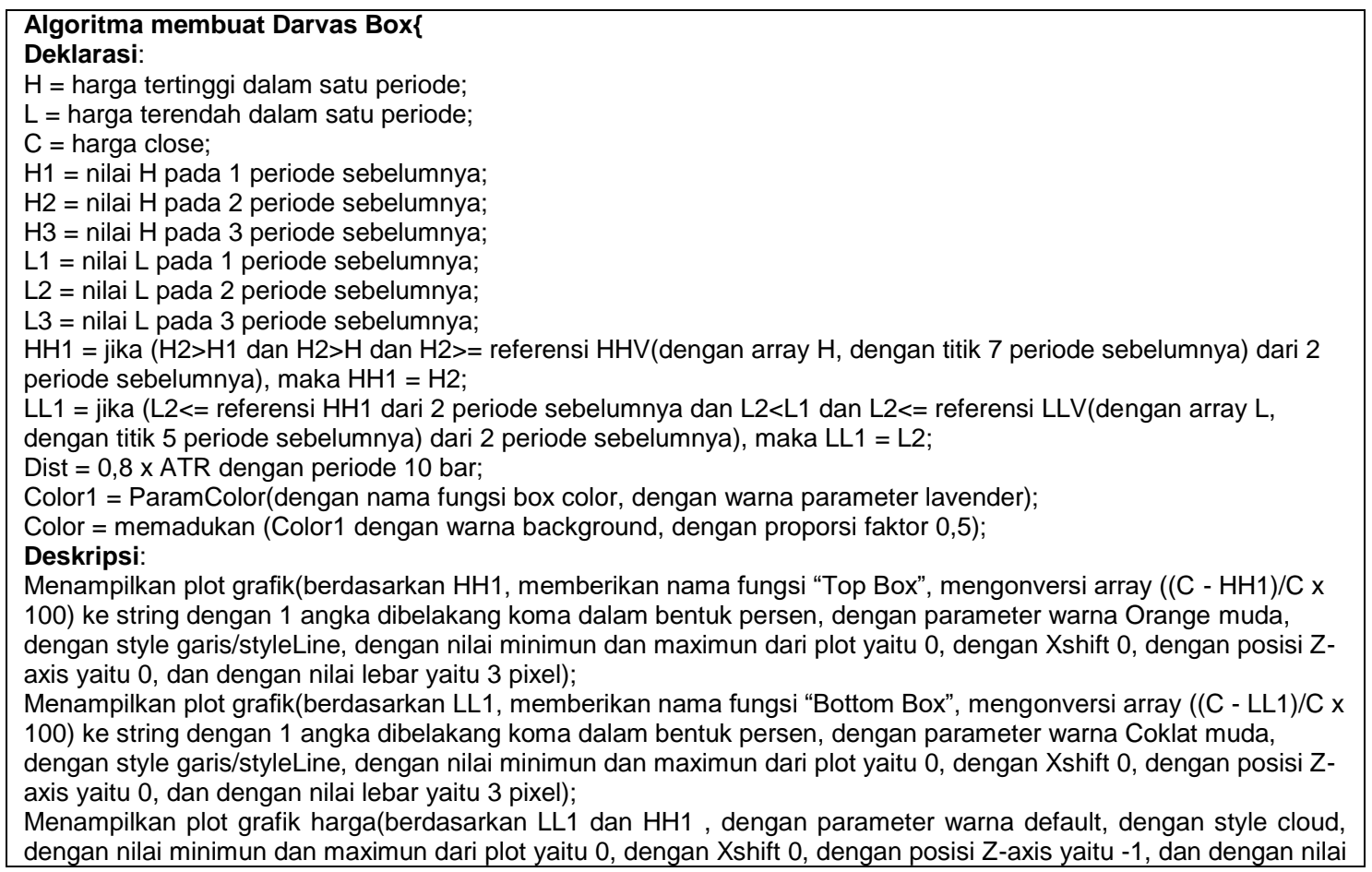


lebar yaitu 3 pixel);

Kode Program 4. Pseudocode membuat Darvas Box

Pseudocode dari algoritma dalam membuat Darvas Box mempergunakan data high, low, dan close pada harga suatu saham yang dipilih sebelumnya agar algoritma dalam membuat Darvas Box dapat berjalan dan menentukan kondisi yang tepat. Output yang dihasilkan dari algoritma dalam membuat Darvas Box berupa kotak imajiner yang terdiri dari dua garis yang membentuk suatu area. Garis atas berfungsi untuk menentukan batasan harga high, sedangkan garis bawah berfungsi untuk menentukan batasan harga low.

\section{Kajian Pustaka}

\subsection{Indikator Support dan Resistance}

Support dan resistance merupakan hal yang penting dalam analisa teknikal karena hal ini memberikan informasi mengenai batas atas dan batas bawah dari sebuah harga yang sedang berjalan [6]. Support adalah batas bawah, sedangkan resistance adalah batas atas. Sebuah harga yang berjalan naik akan dihalangi oleh batas resistance sehingga ketika menyentuh batas tersebut harga akan cenderung kembali turun [6]. Jika batas dengan mudah dilewati, maka harga akan terus bergerak naik [6]. Sebuah harga yang berjalan turun akan dihalangi oleh batas support, sehingga ketika menyentuh batas tersebut harga akan cenderung kembali naik [6]. Jika batas tersebut dengan mudah dilewati, maka harga akan terus bergerak turun [6]. Indikator support dan resistance sangat berperan penting dalam pembuatan algoritma menentukan kondisi buy atau sell dan algoritma darvas box.

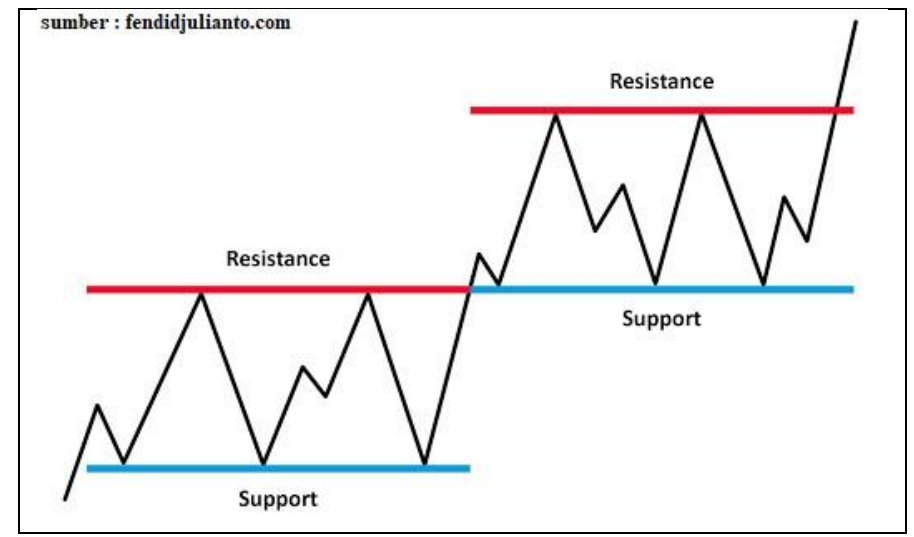

Gambar 3. Garis Support dan Resistance

Gambar 3 merupakan contoh dari garis support dan resistance pada suatu grafik. Rumus pivot point dapat digunakan dalam mencari batas support dan resistance dengan menggunakan rumus pivot point. Rumus pivot point didasarkan pada harga yang terjadi kemarin. Perhitungan pivot point dengan metode yang paling sederhana menggunakan persamaan (1).

$$
\text { Pivot point }=\frac{(H 1+L 1+C 1)}{3}
$$

Dengan $\mathrm{P}$ adalah pivot point, $\mathrm{H} 1$ adalah harga high kemarin, dan $\mathrm{L} 1$ adalah harga low kemarin. Rumus dalam menentukan batas resistance menggunakan persamaan (2) dan (3).

$$
\begin{aligned}
& R 1=(2 x P)-L 1 \\
& R 2=P+(H 1-L 1)
\end{aligned}
$$

Dengan $\mathrm{P}$ adalah pivot point, $\mathrm{H} 1$ adalah harga high kemarin, $\mathrm{L} 1$ adalah harga low kemarin, $\mathrm{R} 1$ adalah batas Resistance 1 periode sebelumnya dan R2 adalah batas Resistance 2 periode sebelumnya. Rumus dalam menentukan batas support menggunakan persamaan (4) dan (5). 


$$
\begin{aligned}
& S 1=(2 x P)-H 1 \\
& S 2=P-(H 1-L 1)
\end{aligned}
$$

Dengan $\mathrm{P}$ adalah pivot point, $\mathrm{H} 1$ adalah harga high kemarin, $\mathrm{L} 1$ adalah harga low kemarin, $\mathrm{S} 1$ adalah batas Support 1 periode sebelumnya dan S2 adalah batas Support 2 periode sebelumnya. Harga open hari ini jika di atas pivot point maka ada kecenderungan harga menuju resistance. Harga open hari ini jika di bawah pivot point, maka ada kecenderungan harga akan bergerak menuju support [7].

\subsection{Indikator Average True Range}

Average True Range (ATR) merupakan indikator analisis teknikal yang dicetuskan oleh J. Welles Wilder. ATR dibuat untuk menganalisa volatilitas pergerakan harga dari suatu saham. ATR diukur berdasarkan rata-rata pergerakan suatu harga dalam periode tertentu. ATR sangat berperan penting dalam pembuatan algoritma menentukan batasan area support dan resistance. Rumus dari indikator ATR menggunakan persamaan (6) dan (7).

$$
\begin{aligned}
& \text { True Range }=\max [(\text { High }- \text { Low }), \text { abs }(\text { High }- \text { Prev Close }), \text { abs }(\text { Prev Close }- \text { Low })] \\
& \text { Average True Range }=\frac{\text { TR1 }+ \text { TR2 }+ \text { TR3 } \ldots+\text { TRn }}{n}
\end{aligned}
$$

True Range adalah nilai max (terbesar) dari harga (High - Low), harga absolute (High Prev Close), harga absolute (Prev Close - Low). Prev Close yang dimaksud adalah harga Close dari periode sebelumnya, sedangkan harga absolute dari rumus yang dimaksud adalah menjadikan hasil perhitungan suatu harga menjadi selalu bernilai positif. ATR merupakan nilai rata-rata dari sejumlah TR (True Range). $\mathrm{N}$ adalah periode yang menjadi patokan sebagai parameter perhitungan ATR [8].

\section{Hasil Dan Pembahasan}

\subsection{Tampilan Sistem}

Penelitian "Optimalisasi Formula Default pada Amibroker untuk Analisis Teknikal pada Pasar Saham" menghasilkan beberapa tampilan halaman dari formula yang belum maupun yang sudah dioptimalisasi dalam bentuk grafik maupun fitur yang diberikan Amibroker untuk analisis teknikal bagi pengguna. Tampilan dari formula maupun fitur dari Amibroker dapat dijelaskan sebagai berikut.

\subsection{Tampilan Grafik Formula Default}

Tampilan grafik formula default merupakan grafik standar yang terdapat pada Amibroker. Grafik default disuguhkan kepada pengguna yang baru membuka dan menggunakan Amibroker. Tampilan grafik yang dihasilkan oleh formula default pada Amibroker dapat dilihat pada Gambar 4.

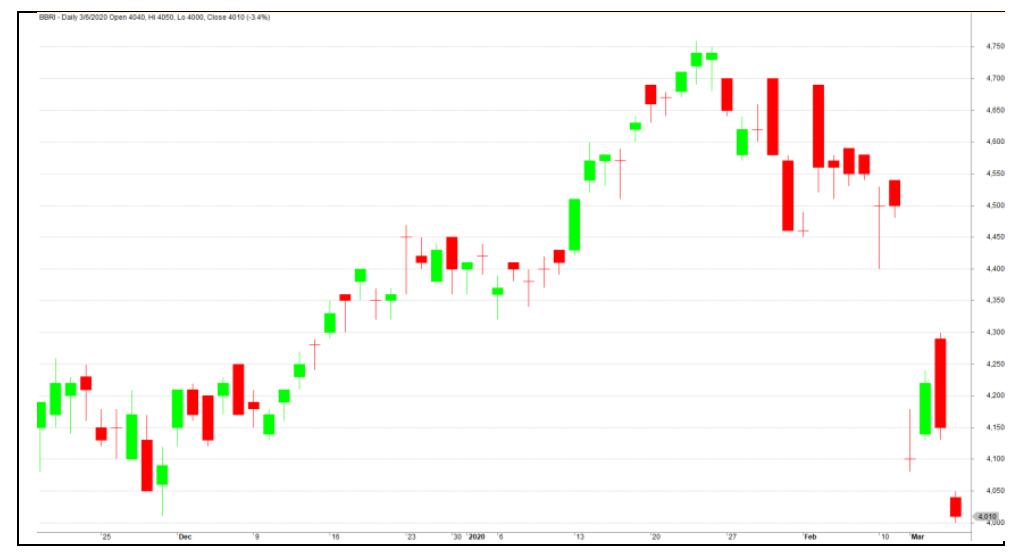

Gambar 4. Tampilan grafik formula Default 
Grafik dari formula tersebut berjenis candlestick yang dimana grafik jenis candlestick merupakan grafik standar dalam menampilkan harga pada suatu saham yang ditentukan sebelumnya. Tampilan grafik formula default pada Amibroker tersebut menampilkan pergerakan harga berdasarkan interval periode yang ditentukan. Pojok kiri atas halaman grafik formula default terdapat informasi mengenai saham yang ditentukan sebelumnya, informasi tersebut dalam bentuk tulisan dan angka yang menunjukan nama saham yang kita tentukan sebelumnya, interval periode yang ditentukan, tanggal, harga open, harga high, harga low, dan harga close dalam bentuk bilangan bulat dan persentase kenaikan/penurunan harga berdasarkan periode sebelumnya. Tampilan grafik formula default pada Amibroker bersifat realtime.

\subsection{Tampilan Grafik Formula Default Setelah Dioptimalisasi}

Didapatkannya tampilan baru dari grafik setelah pengoptimalisasian formula default pada Amibroker. Masih terlihat bagian dari formula default yang berupa candlestick pergerakan harga, dari tampilan grafik formula default pada amibroker yang sudah dioptimalisasi, pengguna sudah dapat memanfaatkan tampilan grafik tersebut dalam hal analisis teknikal. Tampilan grafik yang dihasilkan oleh formula default pada Amibroker setelah dioptimalisasi dapat dilihat pada Gambar 5.

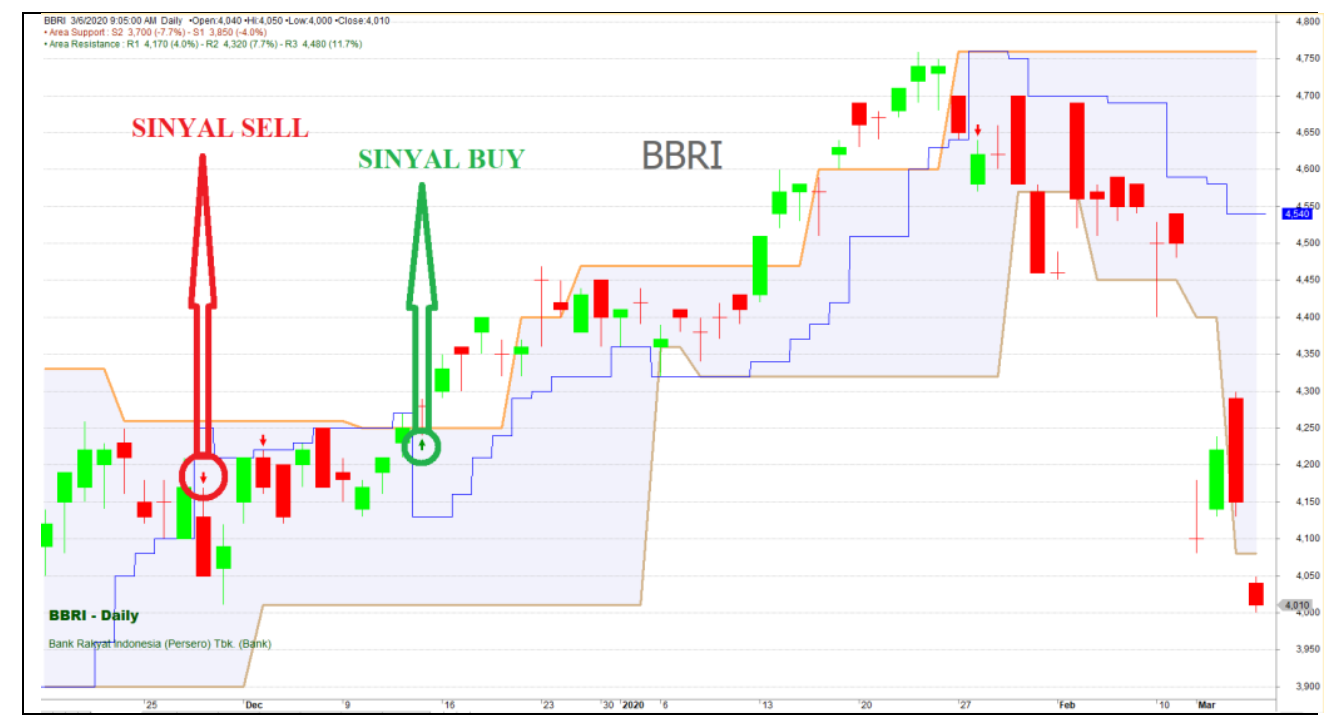

Gambar 5. Tampilan grafik formula Default setelah dioptimalisasi

Perbedaan tampilan grafik formula default sebelum dan sesudah dioptimalisasi yaitu adanya tambahan sinyal kondisi buy atau sell dan darvas box. Sinyal buy atau sell berbentuk simbol panah yang dimana panah berwarna hijau mengarah ke atas menandakan kondisi buy, sedangkan simbol panah berwarna merah mengarah ke bawah menandakan kondisi sell. Darvas box pada tampilan grafik formula default setelah dioptimalisasi berbentuk kotak imajiner yang menyelimuti pergerakan harga dalam bentuk candlestick dari saham yang ditentukan sebelumnya. Sisi pojok kiri atas halaman grafik formula default yang sudah dioptimalisasi pada Amibroker terdapat tambahan yaitu informasi mengenai area support maupun resistance dengan berbagai level agar pengguna dapat mengatur peluang keuntungan dan kerugian yang didapatkan setelah membeli saham tersebut berdasarkan periode saat pengguna tersebut membeli melalui sekuritas secara otomatis. Sama halnya dengan tampilan grafik formula default sebelum dioptimalisasi, tampilan grafik formula default setelah dioptimalisasi pada Amibroker juga bersifat realtime.

\subsection{Tampilan Uji Coba}

Pengujian dari formula default pada Amibroker yang sudah dioptimalisasi sebelumnya dilakukan dengan tujuan untuk mengetahui seberapa optimal formula default pada Amibroker yang sudah dioptimalisasi tersebut. Microsoft Excel digunakan dalam menampung hasil uji coba 
formula default pada Amibroker yang sudah dioptimalisasi secara manual dengan menggunakan tabel. Hasil uji coba dari formula default pada Amibroker yang sudah dioptimalisasi dapat dilihat pada Gambar 6.

\begin{tabular}{|c|c|c|c|c|c|c|c|c|c|c|c|c|c|}
\hline \multirow{4}{*}{$\begin{array}{c}1 \\
\mathrm{No}\end{array}$} & \multirow{4}{*}{$\begin{array}{c}2 \\
\text { Stock }\end{array}$} & \multirow{4}{*}{$\begin{array}{c}3 \\
\text { Tgl. Buy }\end{array}$} & \multicolumn{2}{|c|}{$0.15 \%$ buy } & \multicolumn{3}{|c|}{$0.25 \%$ sell } & \multirow{2}{*}{\multicolumn{6}{|c|}{$\begin{array}{l}1,172,526 \\
11.73 \% \text { growth\% }\end{array}$}} \\
\hline & & & \multicolumn{2}{|c|}{ initial cap: Rp $10,000,000$} & \multirow{3}{*}{ LOT } & \multicolumn{2}{|c|}{ ending cap: $\mathrm{Rp} \quad 11,172,526$} & & & & & & \\
\hline & & & 4 & 5 & & 7 & 8 & 9 & 10 & 11 & 12 & $4.26 \%$ & $-5.30 \%$ \\
\hline & & & BUY $=$ & BUY + FEE $=$ & & SELL $\rightleftharpoons$ & SELL - FEE - & $\mathrm{P} / \mathrm{L}$ & Net \% & Tgl. Sell $=$ & NETDa $=$ & $7-7$ & $1=$ \\
\hline 1 & BBRI & 31-Jan-19 & 3,850 & $4,626,930$ & 12 & 4,020 & $4,811,940$ & 185,010 & $4.00 \%$ & 18-Mar-19 & 33 & $4.00 \%$ & \\
\hline 2 & BBRI & $19-\mathrm{Feb}-19$ & 3,910 & $4,699,038$ & 12 & 4,110 & $4,919,670$ & 220,632 & $4.70 \%$ & 29-Mar-19 & 29 & $4.70 \%$ & \\
\hline 3 & BBRI & 15-Mar-19 & 3,980 & $4,783,164$ & 12 & 4,140 & $4,955,580$ & 172,416 & $3.60 \%$ & 29-Mar-19 & 11 & $3.60 \%$ & \\
\hline 4 & BBRI & 31-May-19 & 4,100 & $4,927,380$ & 12 & 4,390 & $5,254,830$ & 327,450 & $6.65 \%$ & 27-Jun-19 & 20 & $6.65 \%$ & \\
\hline 5 & BBRI & 30-Aug-19 & 4,270 & $5,131,686$ & 12 & 4,060 & $4,859,820$ & $(271,866)$ & $-5.30 \%$ & 25-Sep-19 & 19 & & $-5.3 \%$ \\
\hline 6 & BBRI & $17-0 c t-19$ & 4,050 & $4,867,290$ & 12 & 4,210 & $5,039,370$ & 172,080 & $3.54 \%$ & $24-0 c t-19$ & 6 & $3.54 \%$ & \\
\hline 7 & BBRI & 15-Nov-19 & 4,090 & $4,915,362$ & 12 & 4,290 & $5,135,130$ & 219,768 & $4.47 \%$ & 13-Dec-19 & 21 & $4.47 \%$ & \\
\hline 8 & BBRI & 13-Dec-19 & 4,280 & $5,143,704$ & 12 & 4,420 & $5,290,740$ & 147,036 & $2.86 \%$ & 23-Dec-19 & 7 & $2.86 \%$ & \\
\hline
\end{tabular}

Gambar 6. Tampilan uji coba

Uji coba dilakukan dengan menggunakan data dari salah satu saham yang tergabung dalam index LQ45, yaitu perusahaan bank BRI dengan kode emiten BBRI berdasarkan data periode 2019-2020 dengan interval harian. Dijadikannya area resistance level 2 (R2) dan area support level 2 (S2) sebagai patokan dalam menerima keuntungan maupun kerugian, dan sinyal buy digunakan untuk menentukan aksi beli pada suatu periode. Nominal dari total dana/modal yang dipergunakan dalam uji coba adalah Rp 10.000.000 (sepuluh juta rupiah). Dalam setahun, sinyal buy yang muncul sebanyak 8 sinyal, maka total transaksi yang terjadi sebanyak 8 kali transaksi (buy dan sell). Lot dari setiap transaksi yang terjadi sebanyak 12 lot. Dari total 8 transaksi, didapatkan hasil yaitu berupa 8 transaksi profit (masuk ke area R2) dan 1 transaksi loss (masuk ke area S2) dengan pertumbuhan total dana/modal sebesar $11,73 \%$ atau jika dirupiahkan sebanyak Rp 1.172.526 dalam waktu setahun, yaitu pada tahun 2019-2020.

\subsection{Perbandingan Hasil Uji Coba}

Hasil uji coba formula default pada Amibroker yang sudah dioptimalisasi sebelumnya dengan menggunakan batasan area support dan area resistance dalam menentukan batasan keuntungan maupun kerugian yang akan didapatkan dalam suatu transaksi juga dapat ditarik kesimpulan berupa perbandingan dari setiap hasil uji coba yang terlihat pada tabel 1 .

Tabel 1. Perbandingan hasil uji coba Support dan area Resistance

\begin{tabular}{cccc}
\hline $\begin{array}{c}\text { Batasan area support dan } \\
\text { resistance }\end{array}$ & Win rate & Loss rate & $\begin{array}{c}\text { Pertumbuhan } \\
\text { total dana }\end{array}$ \\
\hline Support 1 dan Resistance 1 & $61 \%$ & $39 \%$ & $3,38 \%$ \\
Support 1 dan Resistance 2 & $49 \%$ & $51 \%$ & $10,41 \%$ \\
Support 1 dan Resistance 3 & $38 \%$ & $63 \%$ & $10,61 \%$ \\
Support 2 dan Resistance 1 & $73 \%$ & $27 \%$ & $2,55 \%$ \\
Support 2 dan Resistance 2 & $61 \%$ & $39 \%$ & $8,37 \%$ \\
Support 2 dan Resistance 3 & $49 \%$ & $51 \%$ & $6,82 \%$ \\
\hline
\end{tabular}

Tabel 1 merupakan perbandingan hasil uji coba yang sudah dilakukan sebelumnya dari setiap area support dan area resistance yang telah dibuat pada formula default pada Amibroker yang sudah dioptimalisasi sebelumnya. Dari tabel 1 dapat dilihat yang mendapatkan win rate tertinggi adalah uji coba dengan batasan area support 2 dan area resistance 1 dengan win rate sebesar $73 \%$. Lalu, yang mendapatkan loss rate tertinggi adalah uji coba dengan batasan area support 1 dan area resistance 3 dengan loss rate sebesar 63\%. Selanjutnya, yang mendapatkan pertumbuhan total dana tertinggi adalah uji coba dengan batasan area support 1 dan area resistance 3 dengan pertumbuhan total dana sebesar 10,61\%. Namun, jika dlihat dari 
perbandingan berdasarkan faktor-faktor yang ada (win rate, loss rate, dan pertumbuhan total dana), dapat disimpulkan hasil uji coba yang paling optimal adalah hasil uji coba dengan menggunakan batasan area support 2 dan area resistance 2 karena hasil uji coba berdasarkan win rate, loss rate, dan pertumbuhan total dana yang didapatkan, hasil uji coba tersebutlah yang paling seimbang dibanding hasil uji coba lainnya. Dikatakan seimbang karena win rate yang didapatkan lebih tinggi dari loss rate dan pertumbuhan total dana yang didapatkan juga tidak terlalu kecil dan masih berada di peringkat ketiga tertinggi jika dibandingkan dengan hasil uji coba lainnya.

\section{Kesimpulan}

Kesimpulan dapat ditarik dari penelitian ini adalah formula default pada Amibroker yang sudah dioptimalisasi sebelumnya telah dapat menampilkan chart/grafik yang dapat memberikan analisis teknikal bagi pengguna berupa kondisi buy atau sell yang ditandai dengan sinyal berupa panah, menampilkan area resistance dan area support untuk membatasi keuntungan dan kerugian yang akan didapatkan dari saham yang dimiliki sebelumnya, dan menampilkan darvas box agar dapat memperkirakan pergerakan harga per periode yang ditentukan dengan mengandalkan Darvas Box sebagai patokan yang tergabung dalam chart.

\section{Daftar Pustaka}

[1] Anonim, "Amibroker," Jurus Cuan, 2019. https://www.juruscuan.com/12Produk/Amibroker/20-Amibroker.

[2] I. W. Supriana, "Optimalisasi Penyelesaian Knapsack Problem Dengan Algoritma Genetika," Lontar Komput. J. Ilm. Teknol. Inf., vol. 7, no. 3, p. 182, 2016, doi: 10.24843/lkjiti.2016.v07.i03.p06.

[3] P. Irvan Arya Purwadana, D. Putra Githa, and D. Purnami Singgih Putri, "Aplikasi Optimalisasi Pengiriman Barang Menggunakan Metode Tabu Search Berbasis Web," J. IIm. Merpati (Menara Penelit. Akad. Teknol. Informasi), vol. 6, no. 3, p. 234, 2018, doi: 10.24843/jim.2018.v06.i03.p10.

[4] K. Meliantari, D. Putra Githa, and N. K. Ayu Wirdiani, "Optimasi Distribusi Produk Menggunakan Metode Cheapest Insertion Heuristic Berbasis Web," J. IIm. Merpati (Menara Penelit. Akad. Teknol. Informasi), vol. 6, no. 3, p. 204, 2018, doi: 10.24843/jim.2018.v06.i03.p07.

[5] A. F. Indriani and M. A. Muslim, "SVM Optimization Based on PSO and AdaBoost to Increasing Accuracy of CKD Diagnosis," Lontar Komput. J. IIm. Teknol. Inf., vol. 10, no. 2, p. 119, 2019, doi: 10.24843/lkjiti.2019.v10.i02.p06.

[6] A. I. Pradana, "Metode Analisis Teknikal dan Fundamental dalam Forex Trading pada PT. Monex Investindo Futures," Dspace, pp. 21-23, 2016.

[7] J. L. Person, Candlestick and Pivot Point Trading Triggers: Setups for Stock, Forex, and Futures Markets. 2011.

[8] D. Vezeris, T. Kyrgos, and C. Schinas, "Take Profit and Stop Loss Trading Strategies Comparison in Combination with an MACD Trading System," J. Risk Financ. Manag., vol. 11 , no. 3, p. 6, 2018, doi: 10.3390/jrfm11030056. 